\title{
Jiu-Jitsu brasileiro: notas sobre a transposição da arte marcial para o esporte espetáculo
}

Brazilian Jiu-Jitsu: notes on the transposition of martial art for sport spectacle

\author{
João Victor de Melo Silva Rodrigues ${ }^{1}$ \\ Fernando Luiz Menezes Araújo \\ Jorge Felipe Columá ${ }^{1}$ \\ Felipe da Silva Triani ${ }^{2, *}$
}

\section{Resumo}

Objetivo: Tecer algumas notas sobre essastransformações que perpassam pela história do Jiu-Jitsu brasileiro e a influência dos espetáculos naexpansão do esporte. Métodos: Foi realizada uma pesquisa de revisão bibliográfica narrativa. Resultados: O nascimento do UFC e do PRIDE, eventos responsáveis pelaexpansão da modalidade, foram conquistas que demandaram grandes desafios. Sobre influência da mídia o UFC implicoutransformações nas regras epontuações para que o esporte desempenhasse sua função de espetáculo para a população mundial. Conclusão: A família Gracie, a institucionalização da luta e os eventos UFC e PRIDE, contribuíram para difusão do jiu-jítsu enquanto esporte espetáculo como hoje se observa.
\end{abstract}

Palavras-chave: jiu-jitsu, história do esporte, lutas, artes marciais.

\section{Abstract}

Objective: To make some notes on these transformations that perpass the history of Brazilian Jiu-Jitsu and the influence of the spectacles in the expansion of the sport. Methods: A bibliographic review was carried out. Results: The birth of the UFC and PRIDE, events responsible for the expansion of the sport, were achievements that demanded great challenges. On the influence of the media the UFC implied transformations in the rules and scores for the sport to play its role as spectacle for the world population. Conclusion: The Gracie family, the institutionalization of the fight and the events UFC and PRIDE, contributed to the diffusion of jiu-jitsu as a spectacle sport, as we can see today.

Keywords: jiu-jitsu, history of sport, fights, martial arts.
Afiliação dos autores

${ }^{1}$ Centro Universitário Augusto Motta UNISUAM, Rio de Janeiro, Rio de Janeiro, Brasil.

${ }^{2}$ Faculdade Gama e Souza, FGS,

Rio de Janeiro, Rio de Janeiro,

Brasil.

${ }^{\star}$ Autor correspondente

Av. Fernando Mattos, 48, Barra da Tijuca, Rio de Janeiro, Brasil. e-mail: felipetriani@gmail.com

\section{Conflito de interesses}

Os autores declararam não haver conflito de interesses.

Processo de arbitragem

Recebido: 25/07/2017 Aprovado: 08/02/2018 


\section{Introdução}

O manuscrito em tela discute o Jiu-Jitsu brasileiro, originado em Manaus e posteriormente no Rio de Janeiro desde 1915, tendo com ícones Carlos e Hélio Gracie ${ }^{1}$, a partir das transformações que sofreu desde sua origem. No início, as competições eram realizadas em uma luta de cada vez, devido ao pouco número de praticantes. No que tange às regras, não tiveram modificações muito drásticas, pois em termos de pontuação nada mudou e o que se pode observar é a forma em que se pontua. Sendo assim, torna-se uma luta de forma estratégica, na qual se preconiza o ponto conquistado.

O Jiu-Jitsu enquanto arte marcial $\left.\right|^{a}$ parece se distanciar da prática atual nas competições, isto é, do Jiu-Jitsu brasileiro. No primeiro, emergente ainda no Japão enquanto arte marcial opraticante visava às finalizações, já na atualidade, o brasileiro, por meio da soma de pontuações, é que se obtém a vitória, e isso conduz a reflexão se a prática ocorre somente visando à pontuação no esporte.

$\mathrm{Na}$ década de 70 , quando se realizavam campeonatos administrados pela família Gracie, o público que assistia as lutas parecia conseguir entender como os movimentos eram realizados, devido à forma mais objetiva dos lutadores. Os golpes evoluíram muito nos últimos anos, as posições ficaram cada vez mais elaboradas e complexas, deixando um pouco difícil o entendimento de quem estava começando no Jiu-Jitsu Brasileiro ${ }^{2}$.

Com o passar dos anos a modalidade parece vir se modificando, e na década de 1970 e 1980, houve um marco histórico para o esporte, foi criada uma finalização chamada triângul ${ }^{\mathrm{b}}$, realizada na guarda, e fez com que mudasse 0 conceito, da luta em si. As passagens de guarda, na qual o oponente esta entre as pernas do adversário, que podemos entender como posição inferior, tenta sair desta situação e ficar superiormente em relação ao outro, e elas foram adaptadas para que fossem passados com os braços simultaneamente ou com os joelhos para que leve a uma posição de conforto. O número de praticantes com o decorrer dos anos, em nosso país, teve um aumento significativo, devido ao trabalho incessante da família Gracie, responsável pela divulgação para outros estados e países do Jiu-Jitsu brasileiro.

No entanto, a arte marcial Jiu-Jitsu que teve grande contribuição dos japoneses, é carregada de valores marciais que implicam a formação da pessoal, isto é, uma ética que rege a prática da arte. Essa arte pode ser encontrada na figura do Samurai, o qual seguia um código de ética, o Bushido, que direcionava sua conduta social ${ }^{3}$. Contudo, a partir da esportivização do Jiu-Jitsu e consequentemente a emergência do Jiu-Jitsu Brasileiro, esses valores parecem ter sido esquecidos e a prática com ênfase na competição exaltada. Logo, percebe-se uma tensão entre o Jiu-Jitsu e o Jiu-Jitsu brasileiro.

Diante desses entendimentos, interessa contribuir com o conhecimento dos profissionais de educação física e mestres ${ }^{c}$, para que venha a acrescentar e expandir o conhecimento da luta dos praticantes e seus formadores e treinadores, mostrando que embora o Jiu-Jitsu Brasileiro seja uma nova luta, seus valores enquanto arte marcial não podem ser eximidos. Portanto, o objetivo deste artigo é tecer algumas notas sobre as transformações que perpassam pela história do Jiu-Jitsu brasileiro e a influência dos espetáculos na expansão da luta para esporte espetáculo.

\section{Métodos}

Para a busca de artigos que compuseram a presente Pesquisa Bibliográfica foi utilizado como base indexadora 0 Google Acadêmico. Essa base foi consultada sem limite de tempo até dezembro de 2016 e as seguintes palavras chaves foram aplicadas na busca em diferentes combinações no

${ }^{\text {a} P r a ́ t i c a ~ m i l e n a r, ~ n a ~ q u a l ~ s e ~ t i n h a ~ a ~ b u s c a ~ d e ~ f i n a l i z a c ̧ o ̃ e s . ~ A s ~ p o n t u a c ̧ o ̃ e s ~ e r a m ~}$ somente em momentos de desempates, caso a luta chegasse ao final.

bomizaça feita na guarda onde o coponte esta entre Finalização feita na guarda, onde o oponente esta entre as suas pernas, e é aplicado um movimento voluntário ou nâ, utilzando uma das pernas pelo pescoço e outra abaixo das axilas, formando um triângulo. Pressionando o pescoço para
baixo e impedindo o fluxo sanguíneo, causando o desmaio.

são Profissionais de Educação Física. Eles são faixas pretas considerando seu grau elevado. idioma Português: "Esporte", "Jiu-jitsu”, “Jiu-Jitsu brasileiro", "Brazilian Jiu-Jitsu" e "Lutas". Como critérios de inclusão foram analisados os seguintes aspectos: a) foram incluídos estudos originais; b) estudos de revisão; c) estudos com viés social. Foram excluídos estudos somente de investigação biológica do esporte.

Os trabalhos tiveram seus títulos e resumos analisados por dois pesquisadores que realizavam a seleção individualmente. Após cada um fazer sua seleção os mesmos se encontravam e os estudos onde ocorreram concordância de aceitação ou rejeição eram incluídos ou retirados da composição da revisão respectivamente. Nos estudos em que ocorreram discordância, os pesquisadores discutiam exaustivamente e minuciosamente até chegarem a um acordo. Os estudos incluídos tinham então seus textos lidos na integra e mais uma vez analisados dentro dos critérios de inclusão e exclusão. As informações retiradas pontualmente dos artigos foram: pontos históricos e principais eventos.

\section{Resultados e Discussão}

\section{Alguns apontamentos sobre o Jiu-Jitsu Brasileiro}

No início, enquanto arte marcial, o Jiu-Jitsu era conhecidopor meio dos monges, como uma prática corpo a corpo, sem a utilização de socos, chutes ou pontapés, o contato era direto e ganhava superioridade com o outro. A prática favorecia as pessoas fisicamente mais fracas, pois era baseado em chaves articulares (alavancas), submetendo o oponente ao solo ${ }^{5}$

No entanto, já no Brasil, a prática passou por um processo de ressignificação por Carlos Gracie e Hélio Gracie. Esse processo implicou a emergência do Jiu-Jitsu Brasileiro. Nele, campeonatos foram organizados e aparentemente vieram crescendo no decorrer dos anos com a institucionalização de confederações e federações, cursos para árbitros e ranking de atletas.

A família Gracie que tinha Carlos Gracie como principal responsável, poiscriou o centro de lutas em Botafogo, no Rio de Janeiro, e seu irmão Hélio Gracie foi um dos grandes mestres, pois assistia às aulas do irmão mais velho, e quando surgiu uma oportunidade, ministrou sua aula colocando algumas coisas diferenciadas na aplicação da luta. Com isso ele se tornou um dos grandes nomes no Brasil junto com seu irmão.

O Jiu-Jitsu brasileiro também era confundido como valetudo $^{d}$ e/ou desafios antes das instituições, campeonatos, pois era uma luta sem regras. Há muita dificuldade de determinar ou encontrar o primeiro campeonato no Brasil, apesar de que, em 1925, Gracie já divulgava sua academia nos jornais com o marketing de que: "se quisesse ter um braço quebrado, procure a academia Gracie.", além de já participar de competições ${ }^{5}$.

Carlos Gracie foi precursor da luta no país, sendo fundamental para que houvesse a instalação da federação e da confederação que fossem responsáveis pela prática, organização e formação de novas academias e centros de lutas, além de caracterizar a luta como esporte, pois houve um processo de institucionalização com a criação dessas entidades. Ele se tornou presidente nas duas entidades. Sendo a Confederação Brasileira de Jiu-Jitsu, a CBJJ, a mais expressiva.

É de grande ressalva a participação do seu irmão Hélio Gracie na difusão Jiu-Jitsu no Brasil, pois segundo Maçaneiro ${ }^{7}$ ele foi aprendendo as técnicas e modificando para que fosse adaptado ao seu tipo físico e facilitado seus movimentos na luta. Essas alterações causaram uma forma diferente de se praticar, algo caracterizou um novo modelo de prática, intitulado como Jiu-Jitsu brasileiro.

De acordo com Rufino e Martins ${ }^{8}$, o Jiu-Jitsu brasileiro foi se desenvolvendo no Brasil, com os desafios propostos pela Família Gracie aos lutadores de outras modalidades, realizado assim uma mistura de modalidades, surgindo assim o MMA (Mixed Martial Arts). O MMA popularizou o Jiu-Jitsu brasileiro, tornando assim uma das principais lutas na prática e, sendo assim, novos adeptos foram conquistados.

\footnotetext{
${ }^{d}$ Competições onde só se ganhava através de finalizações e não havia regras, por isso os desafios eram chamados assim.
} 
Os indicadores de campeonatos de Jiu-Jitsu no Brasil vêm, de acordo com Rufino e Darido $^{4}$, a participação e a importância da CBJJ, para a popularidade, e divulgação do esporte, sendo criado o campeonato Mundial de Jiu-Jitsu em 1996, na cidade do Rio de Janeiro. Em 2007 teve sua primeira edição realizada nos Estados Unidos. Nos anos de 2008 e 2010 foi disputado em Long Beach, na Califórnia, Estados Unidos. A CBJJ criou juntamente com o campeonato mundial, no mesmo ano, o campeonato Brasileiro, que é realizado até hoje, sendo o mais importante no país depois do Mundial.

De acordo com Rufinoe Martins ${ }^{8}$ os eventos esportivos são importantes para promover a modalidade e isso faz com que seja um dos esportes que mais crescem, mas alguns campeonatos internacionais como Campeonato Mundial Profissional ou World Professional Jiu-Jitsu Cup promovido pelo Sheik Tahnoon Bin ZayedAl-Nayan, dos Emirados Árabes Unidos, além do ADCC, o Abu Dhabi Combat Club, promovido pelo mesmo Sheik, oferecem financeiramente uma premiação considerável.

Segundo o site da Confederação Brasileira de Jiu-Jitsu', foram organizados bastantes campeonatos durante $o$ ano de 2016, afirmando assim, a ascensão do Jiu-jitsu no Brasil e no mundo tendo em média mais de 4 competições por mês, sendo internacional ou nacional, organizados todos pela CBJJ e a IBJJF (International Brazilian Jiu-Jitsu Federation).

\section{Eventos e Patrocínios: A Emergência do Esporte Espetáculo}

De acordo com Rufino e Martins ${ }^{8}$ os desafios passaram por um processo de grande popularidade, propostos pela família Gracie e lutadores de modalidades diferentes. A proporção deles foi aumentando, tendo uma popularização no mundo, e realizadas e diversos países, tornando um atrativo muito grande aos competidores, pois era oferecida uma quantidade alta de dinheiro aos participantes.

O mais famoso destes desafios, é conhecido como Ultimate Fighting Championship, ou como popularmente é chamado de UFC, que surgiu a partir da ideia de Helio Gracie eRorion Gracie. Segundo Vasques ${ }^{6}$, Helio Gracie foi morar nos Estados Unidos da América, e continuando sua prática e ensinamentos, desafiou qualquer outro lutador, de qualquer modalidade, oferecendo-os 100 mil dólares para aquele que conseguisse derrota-lo. A luta desenvolvida pelos brasileiros atraiu o interesse do público, e logo um grupo de transmissão de pay-per-view juntamente com os produtores de Hollywood. Nesse contexto,Rorion Gracie inscreveu seu irmão mais novo, Royce, no evento. Como a modalidade brasileira era desconhecida, Royce ganhou as três dos quatros primeiros UFC.

O sucesso causado de imediato do UFC no mundo, fez com que o Japão criasse a PRIDE, em 1997, que contou com a queda do UFC, pela inclusão de algumas regras, forçado pela opinião pública, o evento no Japão teve seu auge e seu sucesso pelo mundo ${ }^{5}$.

O grande número de pessoas que comercializaram 0 produto, como ele é tratado, nunca tinha se visto antes, com transmissões televisivas para vários países. Essa expansão mundial tornou de grande valor comparado ao nível de outros esportes que são mais popularizados. Segundo Vasques ${ }^{6}$ um passo importante para o UFC torna-se um esporte global, após os seus donos realizarem a compra do PRIDE, padronizando as regras e fazendo a aquisição dos pequenos eventos.

Com o tempo, regras foram criadas e o evento passou a ser mais aceito pelas pessoas e a ser exibido pelo pay-per-view na televisão americana, que, em um ano, foi vendido para sete milhões de pessoas. Para popularizar ainda mais o esporte, foi criado pela Spike TV um reality show com os lutadores. Com isso, um grande número de pessoas passou a comprar o programa e, também, a assistir os demais que tratavam do esporte, gerando cifras extraordinárias da exibição desta modalidade esportiva ${ }^{7}$.

O crescimento do UFC gerou um aumento no número de atletas profissionais e comercialização nas competições ocorridas na "era da globalização", de acordo com Vasques ${ }^{4}$, fez com que desenvolvesse um projeto de marketing que definiu novas diretrizes de organização e financiamento dos esportes.

As lutas de artes marciais mistas (MMA) vem sendo regularmente transmitidas na TV aberta brasileira desde meados de 2011, alcançando milhões de telespectadores no país. Desde então, têm feito regularmente parte da programação de uma das principais emissoras do país. Além das lutas, essa emissora produz um reality show, em que lutadores são confinados em uma casa e lutam entre si para que vencedores ganhem contratos profissionais; exibe frequentemente reportagens e programas dedicados à compreensão do MMA e a vida dos atletas como atores dos espetáculos; e já incluiu um personagem lutador de MMA em uma novela, com a clara intenção de popularizar essa luta ${ }^{10-16}$.

Essa espetacularização dos eventos de MMA, representados pelo UFC no mundo, atraindo a população há acompanhar as lutas, aos atletas em suas mídias sociais e tendo em vista o poder de capitação de patrocínios para o evento, a empresa e aos atletas de se profissionalizarem e alcançarem uma boa estabilização financeira.

De acordo com Vasques ${ }^{6}$, para ocorrer uma espetacularização dos esportes em geral, eles sofre mudanças à pedido das mídia, para que eles possam ser consumidos pelos seus telespectadores, que nas lutas fosse diminuídos os tempos sem ação ${ }^{\dagger}$, adequar o tempo de luta, inserir durante o eventos comerciais televisivos que para veicular mensagens dos patrocinadores.

A divulgação e o crescimento desta modalidade e do JiuJitsu principalmente, tem a percepção, da total influencia deste momento da espetacularização do esporte, onde os grandes eventos, junto com a mídia consegue trazer o telespectador a consumir, com a venda de canais fechados, artigos esportivos relacionados as modalidades.

\section{Regras}

De acordo com Rufino e Martins ${ }^{8}$, a finalidade da criação do Jiu-Jitsu, deu-se pela grande necessidade dos guerreiros se utilizarem de praticas sem armas como uma forma de se defenderem, caso por algum acontecimento ficassem sem suas armas ou acessórios de batalha, utilizando o método de defesa pessoal. As regras eram simples e a luta só terminava com uma finalização, e elas eram longas, até que o oponente batesse três vezes com a mão no chão, desistindo e dando a vitória ao oponente. Segundo Maçaneiro ${ }^{7}$, a influência de Hélio, por mais que não haja como saber exatamente, Gracie diz que o mesmo aplicou desenvolveu três diretrizes ou princípios para a seleção e desenvolvimento das técnicas do Jiu-Jitsu Gracie: aplicabilidade na rua, uso eficiente de energia, movimentos naturais do corpo. Com os desafios lançados e com a criação das confederações e federações há uma necessidade de controle aparente, e com toda história de técnicas que o Jiu-Jitsu Brasileiro implantou, deu-se início a criação das regras, pois as lutas tinham que ter um fim, diferenciando-se assim do Jiu-Jitsu enquanto arte marcial.

Com a necessidade de se ter grandes eventos, vamos buscar entender mais pra frente o que eles trouxeram ou não de mudanças, e da busca de patrocínio e parceiros para que os atletas possam vir a ter bom rendimento financeiro. Hoje segundo as regras da CBJJ, o vencedor da luta e aquele que finalizar o oponente, ou que tiver maior pontuação no final do tempo. Os pontos são divididos da seguinte maneira: 4 pontos para montadas e pegadas pelas costas; 3 pontos passagem de guarda; 2 pontos para queda, raspagem, e joelho na barriga; 1 ponto punições e vantagens.

A criação das regras pela CBJJ gerou uma proibição de alguns golpes, preservando a integridade física dos atletas e praticantes. Com a inicialização das divisões porcategorias, os golpes são proibidos de acordo com a idade dos praticantes, apesar de que a precaução com a integridade física dos atletas alguns golpes não podem ser executados na fase adulta, diferente de quando o Jiu-Jitsu teve sua inicialização.

\section{Conclusão}


Em vista dos argumentos apresentados neste estudo, é possível entender os aspectos que puderam contribuir com as transformações ocorridas no decorrer dos anos sobreo JiuJitsu enquanto arte marcial e que, implicaram a emergência do Jiu-Jitsu Brasileiro. Dessa maneira, há de se perceber o quanto a família Gracie, a institucionalização da luta para esporte e eventos como UFC e PRIDE contribuíram para ressignificar a prática do Jiu-Jitsu e criar uma nova luta, o JiuJitsu Brasileiro.

Portanto, este estudo é importante para que os profissionais de educação física e mestres na lutaconheçam essa trajetória, a fim de refletir que embora a luta tenha passado por um processo de ressignificação e a competição seja o grande atrativo da prática enquanto esporte espetáculo, não se deve perder a perspectiva formativa que está presente nos valores da prática, pois ainda que seja uma nova prática, suas raízes se encontram nas artes marciais.

\section{Referências}

1. Mocarzel R; Columá J. Lutas e artes marciais: aspectos educacionais, sociais e lúdicos. Rio de Janeiro: SUAM; 2015.

2. Gracie R. Brazilian Jiu-Jitsu: teoria e técnica. Rio de Janeiro: Ediouro; 2003.

3. Coelho MS; Coelho PRMS; Salgado Filho LN; Columá JF; Triani FS. O samurai como metáfora da sociedade japonesa. Revista Kinesis 2016;34:83-101.

4. Rufino LGB; Darido SC. O jiu-jitsu brasileiro nas três dimensões dos conteúdos nas aulas de educação física escolar. IV Colóquio de Pesquisa Qualitativa em Motricidade Humanas: as lutas no contexto da motricidade. São Carlos: 2009, p. 399-413.

5. GracieH. Gracie Jiu-Jitsu São Paulo: Saraiva; 2010

6. Vasques DG. As artes marciais mistas (MMA) como esporte moderno: entre a busca da excitação e a tolerância à violência. Esporte e Sociedade 2013;8(22)

7. Maçaneiro GGB. Do Judô ao Gracie Jiu-Jitsu: A influência do judô Kodokan na idealização e no desenvolvimento do Jiu-Jitsu brasileiro. [Trabalho de Conclusão de Curso]. Florianópolis: Universidade Federal de Santa Catarina, Curso de Graduação em Educação Física, Centro de Desportos, 2012

8. Rufino LGB; Martins CJ. O jiu-jitsu brasileiro em extensão. Revista Ciência em Extensão2011;7(2):84-101

9. Vasques DG; Beltrão J. MMA e Educação Física Escolar: a luta vai começar. Movimento 2013;19(4):289-308. 